\title{
Frontostriatal White Matter Integrity Predicts Development of Delay of Gratification: A Longitudinal Study
}

\author{
Michelle Achterberg, ${ }^{1,2,3 *}$ - Jiska S. Peper, ${ }^{1,3 *}$ Anna C.K. van Duijvenvoorde, ${ }^{1,3}$ René C.W. Mandl, ${ }^{4,5}$ \\ and Eveline A. Crone ${ }^{1,2,3}$ \\ ${ }^{1}$ Institute of Psychology, Brain and Development Laboratory, and ${ }^{2}$ Leiden Consortium on Individual Development, Leiden University, Leiden $2333 \mathrm{AK}$, The \\ Netherlands, ${ }^{3}$ Leiden Institute for Brain and Cognition, Leiden $2333 \mathrm{AK}$, The Netherlands, ${ }^{4}$ Brain Center Rudolf Magnus, University Medical Center \\ Utrecht, Utrecht 3584 CX, The Netherlands, and ${ }^{5}$ Center for Neuropsychiatric Schizophrenia Research, Psychiatric Center Glostrup, Glostrup DK-2600, Denmark
}

The ability to delay gratification increases considerably across development. Here, we test the hypothesis that this impulse control capacity is driven by increased maturation of frontostriatal circuitry using a fiber-tracking approach combined with longitudinal imaging. In total, 192 healthy volunteers between 8 and 26 years underwent diffusion tensor imaging scanning and completed a delaydiscounting task twice, separated by a 2 -year interval. We investigated dynamic associations between frontostriatal white matter (WM) integrity and delay of gratification skills. Moreover, we examined the predictive value of frontostriatal WM integrity for future delay of gratification skills. Results showed that delay discounting increases with age in a quadratic fashion, with greatest patience during late adolescence. Data also indicated nonlinear development of frontostriatal WM, with relative fast development during childhood and early adulthood and - on average - little change during mid-adolescence. Furthermore, the positive association between age and delay discounting was further increased in individuals with higher WM integrity of the frontostriatal tracts. Predictive analysis showed that frontostriatal WM development explained unique variance in current and future delay of gratification skills. This study adds to a descriptive relation between WM integrity and delay of gratification by showing that maturation of frontostriatal connectivity predicts changes in delay of gratification skills. These findings have implications for studies examining deviances in impulse control by showing that the developmental path between striatum and prefrontal cortex may be an important predictor for when development goes astray.

Key words: adolescence; development; impulsivity; longitudinal; white matter

Significance Statement

During the transition from childhood to adulthood, individuals generally show increased patience and become better in delaying gratification. The exact neural correlates of delay of gratification, however, remain poorly understood. By measuring both frontostriatal white matter (WM) integrity and delay of gratification skills at two time points, we were able to provide links for our understanding of the neural mechanisms underlying this type of impulse regulation capacity. We demonstrate that the ability to delay gratification improves between childhood and young adulthood and this improvement is predicted by the integrity of frontostriatal WM connections. This study adds to a descriptive relation between WM quality and delay of gratification by showing that maturation of frontostriatal connectivity predicts improvements in delay of gratification skills.

\section{Introduction}

Between childhood and adulthood, vigorous advancements in the ability to sustain goal-directed cognition in the face of immediate rewards are observed (Eigsti et al., 2006; Olson et al., 2007; de Water et al., 2014). This ability to delay gratification can be captured in delay-discounting tasks, estimating an individual's

Received Sept. 16, 2015; revised Nov. 27, 2015; accepted Dec. 23, 2015.

Author contributions: J.S.P. and E.A.C. designed research; J.S.P. performed research; M.A., J.S.P., A.C.v.D., and R.C.W.M. analyzed data; M.A., J.S.P., A.C.v.D., R.C.W.M., and E.A.C. wrote the paper.

This work was supported by the Dutch Science Foundation (VENI Grant 451-10-007 to J.S.P.) and the European Research Council (Starting Grant ERC-2010-StG-263234 to E.A.C.).

The authors declare no competing financial interests.

*M.A. and J.S.P. contributed equally to this work. preference for a smaller immediate reward over larger, delayed rewards. A crucial element of these tasks is that the subjective value of a reward decreases when the delay to that reward increases (Critchfield and Kollins, 2001). This capacity has been interpreted as an index of impulse regulation, which changes considerably during adolescence (van den Bos et al., 2015).

A leading hypothesis suggests that maturation of this type of impulse regulation capacity is driven by increased regulatory

Correspondence should be addressed to Jiska S. Peper, Faculty of Social Sciences, Leiden University, Wassenaarseweg 52, 2333 AK Leiden, The Netherlands. E-mail: J.S.Peper@fsw.leidenuniv.nl.

DOI:10.1523/JNEUROSCI.3459-15.2016

Copyright $\odot 2016$ the authors $\quad 0270-6474 / 16 / 361954-08 \$ 15.00 / 0$ 
control of the prefrontal cortex (PFC) over reward-related striatal areas (Figner et al., 2010; Christakou et al., 2011; Casey, 2015). Several studies showed that the striatum is more activated by decisions involving immediately available rewards, whereas prefrontal and parietal cortices are activated when individuals control the temptation to choose immediate rewards (McClure et al., 2004; Somerville et al., 2011; Peters and Buchel, 2011). These results led to the question of whether maturation of prefrontalstriatal white matter (WM) connections concurs with and predicts future-oriented choices across development.

The integrity of connections between the striatum and prefrontal cortex can be assessed using diffusion tensor imaging (DTI). DTI measures the diffusion profile of water molecules in vivo, allowing us to probe microstructural properties of the connecting WM fiber bundles (Le Bihan and Breton, 1985; Jones, 2008). The measurements most commonly derived from DTI are fractional anisotropy (FA), measuring the directional variation of diffusion, and mean diffusivity (MD), measuring the amount of diffusion (Basser and Pierpaoli, 1996). Several DTI studies revealed higher WM integrity across adolescence (Olson et al., 2009; Bava et al., 2010; Simmonds et al., 2014; Peper et al., 2015), although the shape of the trajectory is not yet well understood, some reporting linear and others nonlinear changes (for an overview, see Schmithorst and Yuan, 2010). Moreover, recent studies in adults (Peper et al., 2013) and adolescents (Van den Bos et al., 2015) reported an association between higher frontostriatal WM integrity and increased preference for delayed rewards. From these studies, two important issues remain unresolved: (1) whether the relationship between age and discounting is eliminated-or merely diminished-when brain connectivity is taken into account (Steinberg and Chein, 2015) and (2) whether maturation of frontostriatal WM connections across development is an important predictor of individual development of delay of gratification skills.

To address these questions, the current study followed participants with ages ranging from childhood throughout early adulthood (age 8-26) over a 2-year period. This longitudinal design enabled us to test whether the association between age and discounting behavior is mediated by WM integrity between striatum and PFC and to move beyond a descriptive relation among age, WM integrity, and behavior by testing how brain maturation predicts change in behavior over time.

Consistent with the existing literature, we hypothesized that the ability to delay gratification improves with increasing age (Green et al., 1994; Olson et al., 2007; de Water et al., 2014) and that the integrity of frontostriatal WM matures with increasing age (Olson et al., 2009; Bava et al., 2010; Schmithorst and Yuan, 2010; Simmonds et al., 2014; Peper et al., 2015). The longitudinal design allowed us to test in more detail the shape of change (Braams et al., 2015). In addition, we hypothesized that the increasing effect of age on the ability to delay gratification is further increased in individuals with relatively high frontostriatal WM integrity (positive mediation) (Liston et al., 2006). Ultimately, we hypothesized that frontostriatal WM integrity predicts the improvement of delay gratification over time. That is to say, we expect that frontostriatal WM integrity at time point 1 can predict delay of gratification at time point 2 and that thereby brain maturation precedes and predicts behavioral change.

\section{Materials and Methods}

Participants. The current study was part of a large longitudinal study, referred to as Braintime, conducted at Leiden University, the Netherlands. A total number of 299 participants (ages 8-25) were recruited
Table 1. Demographic characteristics of the sample $(N=192,48.4 \%$ male) at T1 and T2

\begin{tabular}{lcc}
\hline & T1 & T2 \\
\hline Age $(\mathrm{y})$ & $14.32(3.59)$ & $16.28(3.61)$ \\
Age range & $8.01-24.55$ & $9.92-26.62$ \\
Estimated IQ & $110.78(9.81)$ & $108.23(10.20)$ \\
AUC (normalized) & $0.42(0.28)$ & $0.47(0.25)$ \\
FS-tract FA & $0.329(0.020)$ & $0.333(0.020)$ \\
FS-tract MD (mm $2 / \mathrm{s})$ & $0.00080(0.00002)$ & $0.00080(0.00002)$ \\
\hline
\end{tabular}

Data are presented as mean (SD). FS-tract, Frontostriatal tract.

through local schools and advertisements at time point 1 (T1). All participants were fluent in Dutch, right-handed, had normal or correctedto-normal vision, and an absence of neurological or psychiatric impairments. Two years later, at time point 2 (T2), 254 participants were included. From the 254 participants who had measurements on both time points, 14 participants had missing delay discounting data at one of the two time points and 13 participants had missing DTI data at one of the two time points. Thirty-four participants were excluded due to erratic discounting behavior at one of the two time points. Consistent discounting behavior was defined as having at least two decreases in subjective value (indifference points) and not more than one increase in subjective value as time increased (Dixon et al., 2003). The excluded participants had similar demographic characteristics as the included participants (excluded participants: $50 \%$ male; age range $8.21-24.44$; age at T2 $M=$ $16.05, S D=3.66$ ). Behavioral and neuroimaging results with the excluded participants remained unchanged.

There were no outliers in delay discounting data $(Z$-value $<-3.29$ or $>3.29$ ). Outliers in DTI data were winsorized (Tabacknick and Fidell, 2013). The final longitudinal sample (participants included at T1 and T2) consisted of 192 participants ( $48.4 \%$ males; age range $=8.01-26.62$; age at $2 \mathrm{M}=16.31, \mathrm{SD}=3.61$; see Table 1 for demographic characteristics).

Written informed consent was obtained from all participants or participant's parents in the case of minors. All anatomical MRI scans were reviewed and cleared by a radiologist from the radiology department of the Leiden University Medical Center (LUMC). No anomalous findings were reported. Participants received a financial reimbursement for their participation in a larger-scale study (Braams et al., 2014b, 2014a; Peters et al., 2014b, 2014a; van Duijvenvoorde et al., 2016). The institutional review board of the LUMC approved the study and its procedures.

Intelligence quotient (IQ) was estimated with the subsets "similarities" and "block design" at T1 and the subsets "vocabulary" and "picture completion" at T2 of the Wechsler Intelligence Scale for Adults, third edition (WAIS-III) or the Wechsler Intelligence Scale for Children, third edition (WISC-III). Different subsets were used to prevent learning effects. The demographic characteristics of the sample are listed in Table 1. There was no significant correlation between estimated IQ and delay of gratification skills at T1 $(r=0.0195, p=0.195)$ nor at T2 $(r=0.113, p=$ $0.119)$. Therefore, IQ was not included as a covariate in the remaining analyses.

Delay-discounting task. A computerized version of a hypothetical delay-discounting task described by Peper et al. (2013) was used, based on the paradigm explained by Richards et al. (1999). Subjects were asked to make a series of choices between either a small, immediately available amount of money or $€ 10$ available after a delay (i.e., "What would you rather have: $€ 2$ right away or $€ 10$ in $30 \mathrm{~d}$ ?"). Discounting was assessed at 4 delays $(2,30,180$, and 365 d later). Trials with different delays were presented in a mixed fashion. Furthermore, the task was adaptive: after the choice for the immediately available money, this amount was decreased on a next trial, whereas if the delayed money was preferred, the amount of immediately available money on the next trial was increased (decreasing adjustment algorithm; Du et al., 2002).

The amount of immediately available money that the participant considered to be equivalent to the $€ 10$ delayed reward was taken to indicate the subjective value of the delayed rewards. Based on these so called "indifference points," the area under the discounting curve (AUC) was obtained, an often-used measure of amount of discounting (Myerson et al., 2001). The normalized AUC ranges from 0 (complete discounting) to 

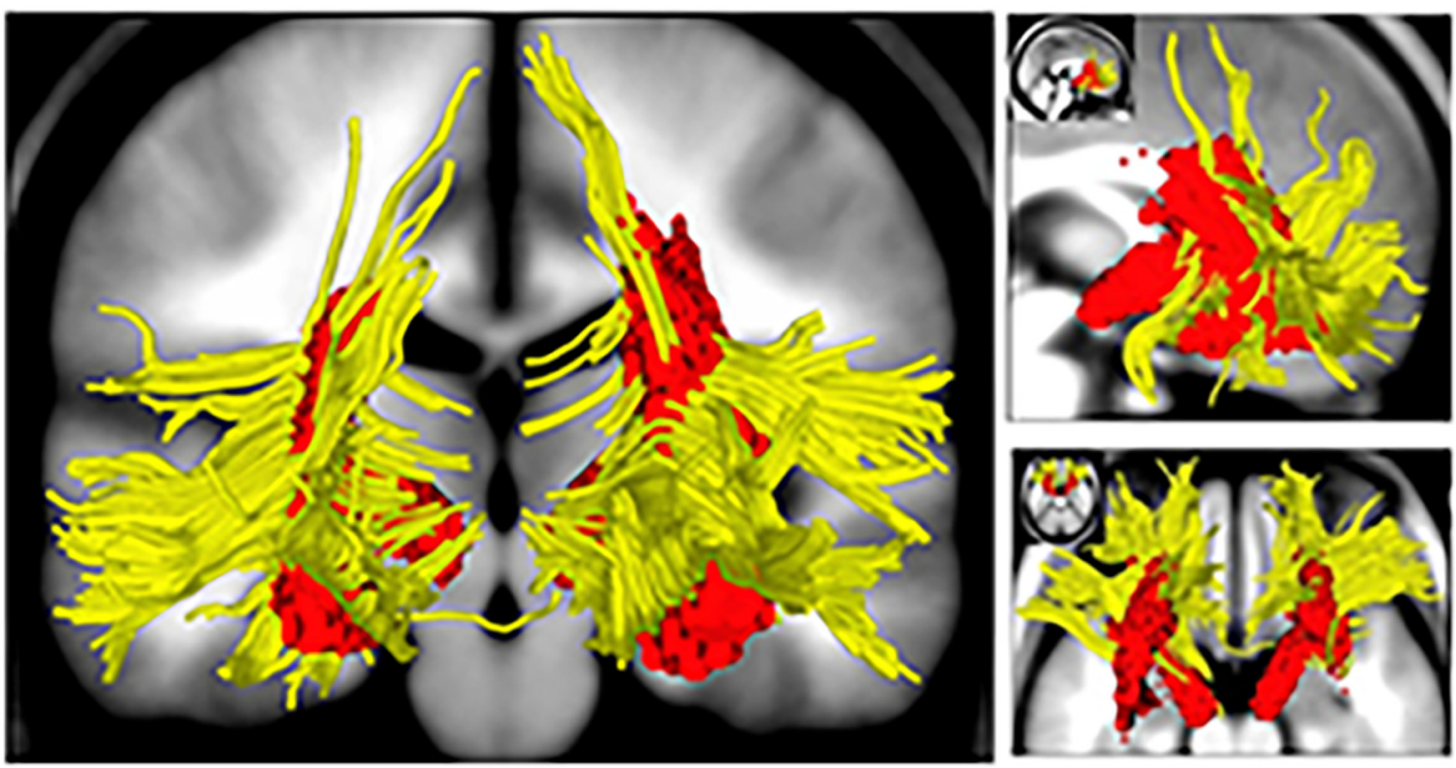

Figure 1. The frontostriatal WM tract within an individual subject is displayed in yellow, with the striatum and PFC as inclusion ROIs. Red regions display the V0I. The VOI was created across the whole sample; a voxel was included when it had a frontostriatal fiber running through in at least $50 \%$ of the total sample.

1 (no discounting). The smaller the AUC, the faster people discount the delayed reward and the more impulsive (or delay aversive) they are. The task was presented as a hypothetical delay-discounting task. However, several studies have shown that choices on a hypothetical delaydiscounting task substantially and significantly correlate ( $r$ 's up to 0.74 ) with choices on a delay discounting task with real rewards in adults (Bickel et al., 2009; Scheres et al., 2010).

Imaging acquisition and processing. The same imaging acquisition was used as described in Peper et al. (2013). Scans were acquired on a 3 tesla Philips Achieva MRI system. Two transverse diffusion weighted imaging (DWI) scans were obtained with the following parameter settings: 30 diffusion-weighted volumes with different noncollinear diffusion directions with $b$-factor $1000 \mathrm{~s} / \mathrm{mm}^{2}$ and 5 diffusion-unweighted volumes $\left(b\right.$-factor $\left.0 \mathrm{~s} / \mathrm{mm}^{2}\right)$; anterior-posterior phase encoding direction; parallel imaging SENSE factor $=3$; flip angle $=90$ degrees; 75 slices of $2 \mathrm{~mm}$; no slice gap; reconstruction matrix $128 \times 128 ; \mathrm{FOV}=240 \times 240 \mathrm{~mm}$; $\mathrm{TE}=69 \mathrm{~ms}$; TR $=7315 \mathrm{~ms}$; total scan duration $=271 \mathrm{~s} \mathrm{per} \mathrm{DWI} \mathrm{set.} \mathrm{The}$ second DWI set had identical parameter settings as used for the first set except that it was acquired with a reversed $k$-space readout direction (posterior-anterior phase encoding direction), enabling the removal of susceptibility artifacts during postprocessing (Andersson et al., 2003). During scanning, the FOV was angulated according to the anterior commissure-posterior commissure line and diffusion gradients were adjusted accordingly during data processing. Subsequently, diffusion scans were realigned to the averaged b0 scan and corrected for motion, eddy current, and susceptibility distortions (Andersson and Skare, 2002; Andersson et al., 2003). A tensor was fitted to the diffusion profile in each voxel using a robust tensor fitting method to correct for possible effects of cardiac pulsation and head motion (Chang et al., 2005; Chang et al., 2012). The main diffusion direction was determined as the principal eigenvector of the eigenvalue decomposition of this fitted tensor.

Based on the eigenvalue decomposition, two measures derived from the diffusion tensor were computed: FA, which measures the directional variation of diffusion and ranges from 0 (no preferred diffusion direction) and 1 (highly preferred diffusion direction) and $\mathrm{MD}$, measuring the amount of diffusion (Basser and Pierpaoli, 1996).

WM pathways were reconstructed using deterministic streamline tractography, based on the Fiber Assignment by Continuous Tracking (FACT) algorithm (Mori et al., 1999). Within each voxel of the cerebral WM, 8 streamlines were started, following the computed diffusion directions from voxel to voxel until one of the stopping criteria was reached (FA $<0.1$, sharp turn of 45 degrees or more, or exceeding brain tissue).
This procedure resulted in a collection of reconstructable WM tracts from which fiber tracts of interest could be selected.

Frontostriatal volume of interest. We used a "volume of interest" (VOI) to measure frontostriatal WM tracts as described by Peper et al. (2013). The VOI requires that the fiber tracts that are reconstructed for each subject in native space are put into model space to create the VOI (for a detailed description, see Peper et al., 2013). In short, tracts were required to run through both the striatum and PFC to be included as frontostriatal WM. Inclusion regions of interest (ROIs) were based on the automatic anatomical labeling (AAL) template (Tzourio-Mazoyer et al., 2002), including the caudate, putamen, and pallidum (AAL regions 71-76), as well as the dorsolateral, ventrolateral, and ventromedial prefrontal cortices (AAL regions 5-10, 13-16, and 25-28). The ROIs were dilated with two voxels in all directions to ensure that they penetrate the WM. Exclusion ROIs were the genu of the corpus callosum (manually delineated on the midsagittal slice), the uncinate fasciculus, and the longitudinal fascicules (manually delineated by a plane through the temporal lobes where the amygdala was located). For fiber selection, all ROIs had to be defined only once on the model brain. For an individual example of frontostriatal fiber tracts, see Figure 1. All voxels within the selected frontostriatal tracts were flagged, resulting in individual binary maps of frontostriatal tracts (in model space) for each participant of the sample on both time points T1 and T2. Subsequently, the VOI was created for frontostriatal tracts of the sample: Every voxel within the frontostriatal tract should have a fiber running through in at least $50 \%$ of the sample (i.e., thresholded at $50 \%$; Fig. 1). Then, this particular voxel was flagged and added to the VOI. The left and right hemisphere were combined to ensure comparability with earlier reports (Liston et al., 2006; de Zeeuw et al., 2012; Peper et al., 2013; van den Bos et al., 2015) that did not report hemispheric differences in relation to impulsive behavior.

Within the VOI of the frontostriatal tract, DTI metrics (FA and MD) were calculated for each individual subject of the whole sample.

Global WM. As a control measure of global WM development and to test for specificity of the contribution of frontostriatal WM tracts to delay discounting behavior, WM tracts of the whole brain-excluding the frontostriatal tracts-were examined as well.

Statistical analyses. Statistical analyses were conducted with SPSS version 21 and in R version 3.1.1 (Pinheiro et al., 2013). The contribution of sex and intelligence to delay of gratification skills (AUC normalized) were explored using independent-sample $t$ tests and Pearson's correlation in SPSS. Pearson's correlation in SPSS was also used to investigate the stability of delay of gratification skills (AUC normalized) and WM 
Table 2. AIC and BIC values for null, linear, quadratic, and cubic age models fitted separately for delay of gratification skills (AUC normalized), FA of the frontostriatal (FS) tract, and MD of the FS-tract

\begin{tabular}{|c|c|c|c|c|c|c|c|c|}
\hline \multirow[b]{3}{*}{ Measure } & \multicolumn{8}{|l|}{ Model } \\
\hline & \multicolumn{2}{|l|}{ Null } & \multicolumn{2}{|l|}{ Linear } & \multicolumn{2}{|l|}{ Quadratic } & \multicolumn{2}{|l|}{ Cubic } \\
\hline & AIC & $\mathrm{BIC}$ & AIC & $\mathrm{BIC}$ & AIC & $\mathrm{BIC}$ & AIC & $\mathrm{BIC}$ \\
\hline AUC (normalized) & 19.19 & 31.04 & 2.57 & 18.37 & 0.36 & 20.12 & 0.29 & 23.99 \\
\hline FA of the FS-tract & -2000.71 & -1988.86 & -2050.19 & -2034.39 & -2055.72 & -2035.97 & -2062.04 & -2038.34 \\
\hline MD of the FS-tract & -7168.88 & -7157.02 & -7183.25 & -7167.45 & -7186.82 & -7167.07 & -7195.07 & -7171.36 \\
\hline
\end{tabular}

Preferred models are highlighted in bold.

a

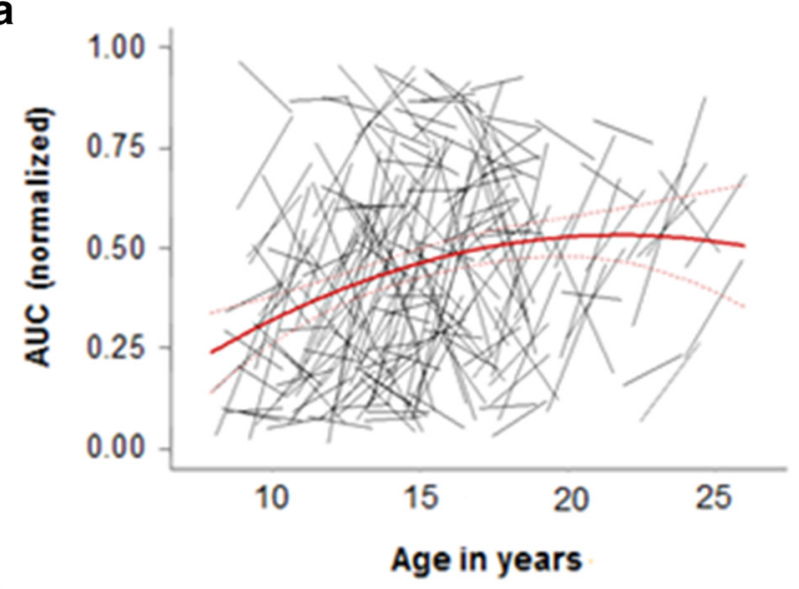

b
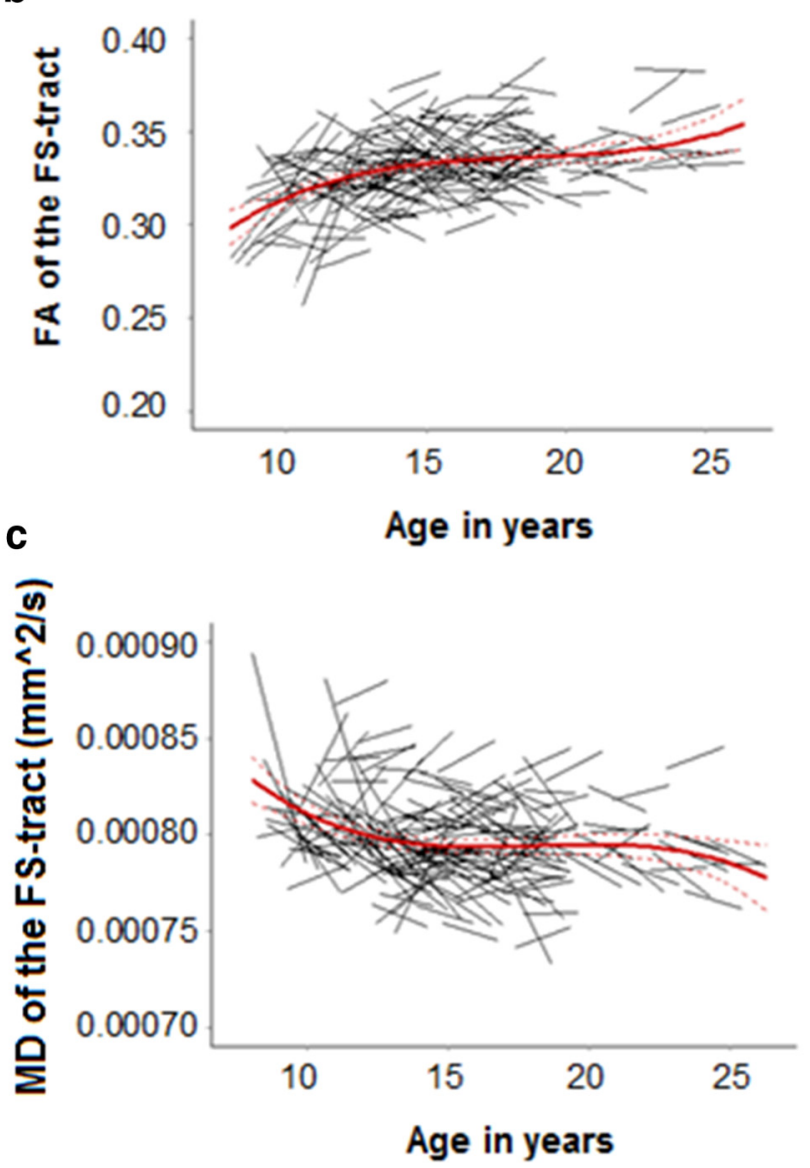

Figure 2. Individual variability over time for AUC normalized (a), FA (b), and MD (c). Every line represents one individual, with $A U C / F A / M D$ at $T 1$ at the left side of the line and AUC/FA/MD at $\mathrm{T} 2$ at the right side of the line. The solid lines display the predicted value of the best-fitting age model. Dotted lines represent the $95 \% \mathrm{Cl}$. integrity (FA and MD) over time. Furthermore, mediation analyses were performed to test whether the relation between age and delay discounting was mediated by frontostriatal WM integrity, measured by FA and MD. For correct comparison between FA and MD, we used $z$-values in the mediation analyses. The present study used a bootstrapping approach to mediation as implemented in the SPSS macros of Preacher and Hayes (2008). Confidence intervals (95\% CI) were estimated using the biascorrected bootstrap method (number of resamples $=10000$ ) implemented in the macros.

Mixed models were used to investigate age-related change (linear, quadratic, or cubic) in delay of gratification skills (AUC normalized) and frontostriatal WM integrity (FA and MD). Analyses were performed with the nlme package in R (Pinheiro et al., 2013). Mixed models are particularly useful in longitudinal studies because these datasets have time points within participants and the mixed-model approach can recognize this type of data dependency. To test for developmental effects, we followed a formal model-fitting procedure (for a similar approach, see Braams et al., 2015). We started by using a null model that only included a fixed and a random intercept to allow for individual differences in starting points and to account for the repeated nature of the data. We fitted three polynomial age models with increasing complexity that tested the grand mean trajectory of age; that is, a linear, quadratic, and cubic age trend. Akaike Information Criterion (AIC; Akaike, 1974) and Bayesian Information Criterion (BIC; Schwarz, 1978), both standardized modelfit metrics, were used to compare the different models. Lower AIC and BIC values indicates a better model fit. Log likelihood ratio tests were used between nested models to test which age trend best described the data. Reported $p$-values for the mixed models are based on log likelihood ratio tests. All models were fit with full information maximum likelihood estimates.

Ultimately, linear regression models in SPSS were used to test longitudinal prediction models. In specific, we tested whether frontostriatal WM integrity (FA and MD) at T1 could predict delay of gratification skills at T2 while taking into account delay of gratification performance at baseline.

\section{Results}

Age effects on delay discounting

Cross-sectional data showed that advanced age was related to a larger AUC (normalized), meaning less steep discounting of delayed rewards with age, at both T1 $(r=0.207, p=0.004)$ and at $\mathrm{T} 2(r=0.204, p=0.004)$. Delay of gratification skills at T1 were positively correlated with delay of gratification skills at T2 $(r=$ $0.543, p<0.001)$.

The longitudinal analyses, testing for linear, quadratic, and cubic changes in delay discounting, showed that age-related change in delay of gratification skills (AUC normalized) was best described by a quadratic age-model (age ${ }^{1}: \beta=.1 .269, p<0.001$; age $^{2}: \beta=-0.568, p=0.040$; Table 2). This model indicates a "peak" in AUC during late adolescence/early adulthood (Fig. 2a). We also performed the analyses without the group of young adults ( $>18$ years) to check for possible biases in model-fitting results due to a relative small sample size $(n=21)$. However, age-related change in delay of gratification skills (AUC normalized) was, conforming the analysis on the total sample, best de- 
scribed by a quadratic age model (age ${ }^{1}: \beta=.1 .274, p<0.001$; age $^{2}: \beta=-0.509, p=0.033$ ). Finally, with respect to behavioral performance, we tested potential sex differences. In the current dataset, there were no significant sex or sex $\times$ age interaction effects in delay of gratification.

\section{Age effects on the frontostriatal tract}

Cross-sectional data at T1 and T2 showed that WM integrity of the frontostriatal tract increased with age. Age was significantly positively correlated with FA at T1 $(r=0.440, p<0.001)$ and at T2 $(r=0.351, p<0.001)$ and significantly negatively correlated with $\mathrm{MD}$ at $\mathrm{T} 1(r=-0.220, p=0.002)$, but not at T2 $(r=-0.089, p=0.089)$. Moreover, WM integrity measures were positively correlated between T1 and T2 (FA: $r=0.611, p<$ 0.001; MD: $r=0.583, p<0.001)$.

Longitudinal analyses revealed that age-related change in WM integrity (FA and MD) was best explained by a cubic age model

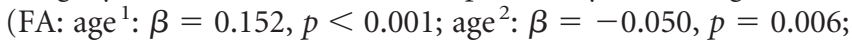
age $^{3}: \beta=0.047, p=0.004$; MD: age ${ }^{1}: \beta=-0.00010, p<0.001$; age $^{2}: \beta=0.00005, p=0.018$; age ${ }^{3}: \beta=-0.00007, p=0.001$; Table 2). More specifically, our data indicate that FA mostly increased during childhood and early adulthood. The reversed pattern of FA changes was observed for MD (Fig. $2 b, c)$. However, when the analyses performed on the sample of 8 - to 18 -year-old participants only, age-related change in WM integrity was best explained by a quadratic age-model (FA: age ${ }^{1}: \beta=0.137, p<$ 0.001 ; age $^{2}: \beta=-0.048, p=0.005 ;$ age $^{3}: \beta=0.022, p=0.1220$; MD: age ${ }^{1}: \beta=-0.00011, p<0.001 ;$ age $^{2}: \beta=0.00005, p=$ 0.015 ; age $^{3}: \beta=-0.00003, p=0.131$ ). Additional analyses showed that there were no significant sex or sex $\times$ age interaction effects in WM integrity (nor in FA or in MD).

\section{Mediation analyses}

To investigate the relation between age and WM integrity in explaining variance in delay of gratification skills, we performed mediation analyses using the method of Preacher and Hayes (2008). At T1, the effect of age on delay of gratification (path c: $\beta$ $=0.016, p=0.004$ ) was fully mediated by FA (path a: $\beta=.123$, $p<0.001$; path b: $\beta=0.067, p=0.0019$; path $c^{\prime}: \beta=0.008, p=$ 0.195 ; mediation effect $\mathrm{a}^{\star}$ b: $95 \%$ CI $0.0034-0.0140 ; p=0.004$; Fig. $3 a$ ). Furthermore, the effect of age on delay of gratification skills (path c: $\beta=0.016, p=0.004$ ) was significantly mediated by $\mathrm{MD}$ (path a: $\beta=-0.0614, p=0.002$; path b: $\beta=-0.059, p=$ 0.003 ; path $c^{\prime}: \beta=0.012, p=0.026$; mediation effect $\mathrm{a}^{*} \mathrm{~b}: 95 \% \mathrm{CI}$ $0.0012-0.0076 ; p=0.030)$.

Partly overlapping results were found at T2: FA was a significant mediator of the association between age and delay of gratification skills (path c: $\beta=0.014, p=0.005$; path a: $\beta=0.097, p<$ 0.001 ; path $\mathrm{b}: \beta=0.038, p=0.047$; path $\mathrm{c}^{\prime}: \beta=0.011, p=0.046$; mediation effect $\mathrm{a}^{\star}$ b: $95 \%$ CI $0.0004-0.0081 ; p=0.061$; Fig. $3 b$ ). However, MD within the frontostriatal-tract did not mediate the association between age and delay of gratification skills (path c: $\beta=0.014, p=0.005$; path a: $\beta=-0.035, p=0.083$; path $\mathrm{b}: \beta=$ $0.012, p=0.488$; path $c^{\prime}: \beta=0.015, p=0.004$; mediation effect $\mathrm{a}^{\star} \mathrm{b}$ : $\left.95 \% \mathrm{CI}=-0.0028-0.0006 ; p=0.517\right)$. Therefore, the relation between age and delay of gratification performance was mediated by WM integrity within the frontostriatal tract at both time points.

\section{Longitudinal prediction}

To test whether WM integrity of the frontostriatal tract could predict future discounting behavior, we performed a linear regression analysis with delay of gratification skills (AUC normal-
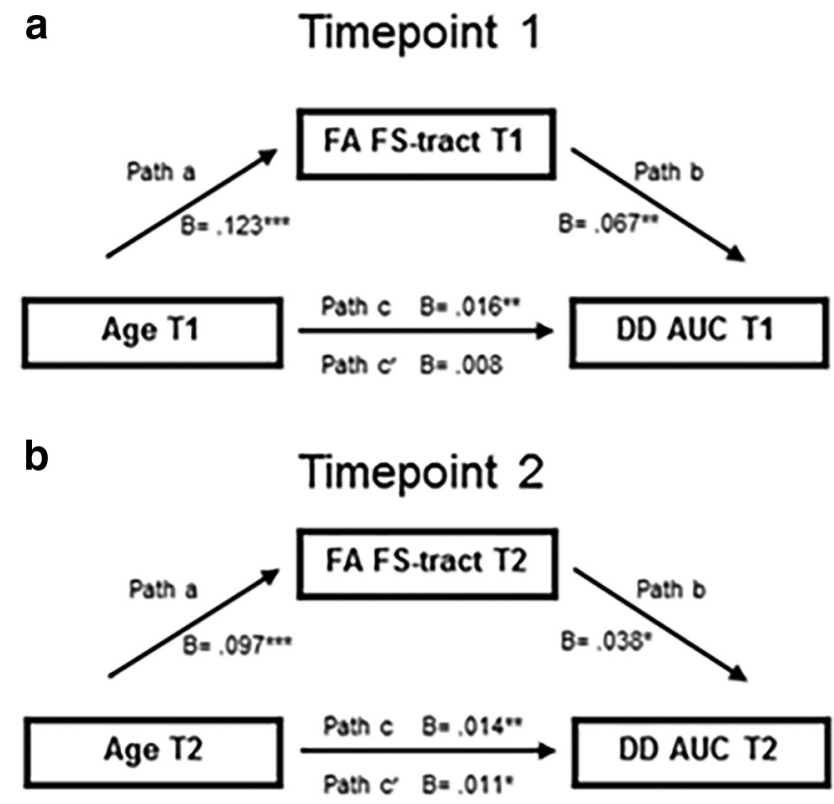

Figure 3. Mediation models. The relation between age and delay of gratification skills is partly mediated by FA at $\mathrm{T} 1(\boldsymbol{a})$ and at $\mathrm{T} 2(\boldsymbol{b})$. Values are standardized regression coefficients and asterisks indicate significance coefficients $\left({ }^{*} p<0.05\right.$; ${ }^{* *} p<0.01$; ${ }^{* * *} p<0.001$ ).

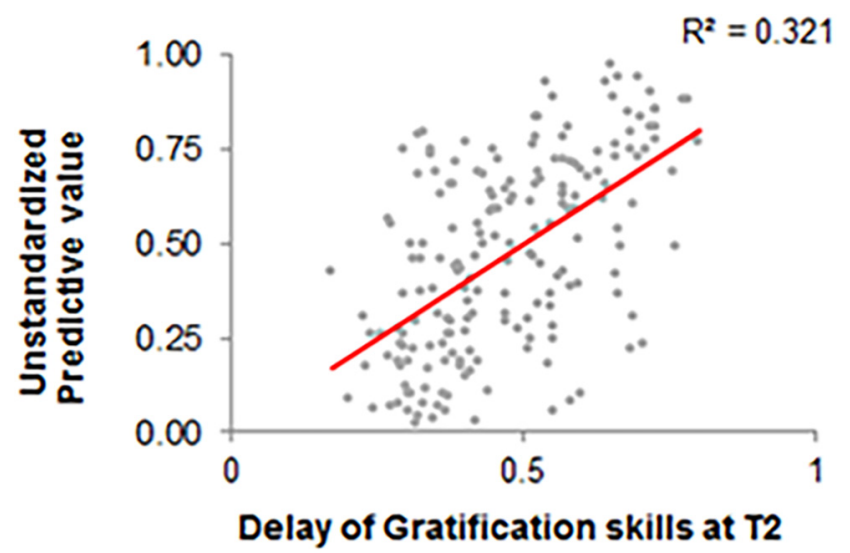

Figure 4. Delay of gratification skills (AUC normalized) at T2 was predicted by delay of gratification skills (AUC normalized) at T1 and FA of the frontostriatal tract at T1. The $y$-axis displays the unstandardized predictive value of the regression model with AUC (normalized), age, FA of the frontostriatal tract, and MD of the frontostriatal tract at $\mathrm{T} 1$ as predictors.

ized), age, FA, and $\mathrm{MD}$ at $\mathrm{T} 1$ as predictors for delay of gratification skills at $\mathrm{T} 2$. The results showed that, in addition to delay of gratification skills at T1 $(\beta=0.504, p<0.001)$, FA was a significant predictor $(\beta=0.158, p=0.034)$ for delay of gratification skills at T2 $\left(R^{2}\right.$ total model $=0.321, R^{2} \mathrm{FA}=0.017$; Fig. 4 , Table 3$)$. Age at T1 and MD did not significantly predict future discounting behavior. The same analyses were performed with nonlinear age changes $\left(\mathrm{age}^{2}\right.$ and $\mathrm{age}^{3}$ ). On top of delay of gratification skills and FA at T1, age ${ }^{2}$ and age ${ }^{3}$ did not significantly predict future discounting behavior. Therefore, while accounting for behavioral performance at baseline, FA within the frontostriatal tract explains unique variance in future delay of gratification skills.

We also investigated whether delay of gratification skills at T1 was predictive of frontostriatal WM integrity at T2. We entered FA at T2 as dependent variables and FA, age, and delay of gratification skills (AUC normalized) at $\mathrm{T} 1$ as predictor. The same 
Table 3. Linear regression predicting delay of gratification skills at $\mathrm{T} 2$ using delay of gratification skills (AUC normalized), age, FA, and MD at T1

\begin{tabular}{lrrrr}
\hline & \multicolumn{1}{c}{ B } & \multicolumn{1}{c}{ SE } & $\beta$ & \multicolumn{1}{l}{$p$} \\
\hline Constant & -0.996 & 0.772 & & 0.199 \\
T1 AUC (normalized) & 0.463 & 0.059 & 0.504 & 0.000 \\
T1 Age & 0.003 & 0.005 & 0.048 & 0.473 \\
T1 FA of the FS-tract & 1.970 & 0.922 & 0.158 & 0.034 \\
T1 MD of the FS-tract & 726.143 & 766.871 & 0.064 & 0.345 \\
\hline
\end{tabular}

FA of the frontostriatal (FS) tract explains $8.8 \%$ of the variance in delay discounting performance at T2 without correcting for discounting performance at $\mathrm{T} 1$. The proportion of explained variance by FA of the FS-tract at $\mathrm{T} 1$ in delay discounting performance at $\mathrm{T} 2$, on top of delay discounting behavior at $\mathrm{T} 1$, is $2 \%$.

analyses were conducted with MD at T2 as a dependent variable. Linear regression analyses showed that both $\mathrm{FA}(\beta=-0.018, p=$ $0.763)$ and $\mathrm{MD}(\beta=-0.008, p=0.895)$ at T2 were not significantly predicted by delay of gratification skills at T1.

\section{Global WM effects}

To test for the specificity of the frontostriatal tract in predicting discounting behavior, we performed a similar analysis with global FA and MD (i.e., all WM connections excluding the connections marked as frontostriatal tract). Longitudinal analyses revealed that age-related change in global WM integrity (FA and MD) was also best explained by a cubic age-model (FA: age ${ }^{1}: \beta=0.225$, $p<0.001 ;$ age $^{2}: \beta=-0.095, p<0.001 ;$ age $^{3}: \beta=0.047, p=$ 0.004; MD: age ${ }^{1}: \beta=-0.00010, p<0.001 ;$ age $^{2}: \beta=0.00005$, $p=0.018$; age $\left.^{3}: \beta=-0.00007, p=0.001\right)$. Age-related change between 8 and 18 years was - similar to the frontostriatal tractsbest explained by a quadratic age model (FA: age ${ }^{1}: \beta=0.227, p<$ 0.001 ; age $^{2}: \beta=-0.041, p<0.001 ;$ age $^{3}: \beta=0.017, p=0.073$; MD: age ${ }^{1}: \beta=0.00005, p=0.063$; age $^{2}: \beta=0.00009, p<0.001$; age $^{3}: \beta=-0.00002, p=0.123$ ). Importantly, the linear regression analysis with delay of gratification skills (AUC normalized), age, $\mathrm{FA}$, and $\mathrm{MD}$ at $\mathrm{T} 1$ as predictors for delay of gratification skills at T2 showed that global FA $(\beta=0.059, p=0.539)$ and $\mathrm{MD}(\beta=$ $0.060, p=0.802$ ) did not predict future discounting behavior.

\section{Discussion}

Development in risk-taking tendencies and impulsive control have been attributed to an imbalance between subcortical and cortical brain regions (Somerville et al., 2010; Casey, 2015), but very few studies have examined the anatomical connections between these areas in relation to impulsive choice. One important dimension of impulsivity is the ability to delay gratification (Whelan et al., 2012). Next to examining developmental patterns in impulsive choice and frontostriatal WM integrity, the current study aimed to test whether the integrity of frontostriatal WM connections mediated and predicted the ability to delay gratification across development. We were able to demonstrate that agerelated increases in the preference for delayed rewards (i.e., less impulsive choice) were significantly dependent on a better quality of connections between the PFC and striatum. Moreover, the longitudinal analysis revealed that stronger connectivity between striatum and PFC predicted less impulsive choices 2 years later.

The first question addressed in this study was to test age-related change in the ability to delay gratification between childhood and young adulthood. From our results it appears that delay of gratification is largest around late adolescence, followed by a slight decline in early adulthood. This finding fits well with a recent study on agerelated changes in discounting of real rewards (Scheres et al., 2006). It appears that there is a gradual increase in delay of gratification skills between childhood and late adolescence, reaching a plateau in late adolescence/early adulthood. Prior studies also showed the most reward-oriented behavior in mid-adolescence and a steep increase in late adolescence in self-control (Steinberg et al., 2008; Olson et al., 2009; de Water et al., 2014). A possible explanation that follows from these findings is that adolescents, more so than children, flexibly apply self-control for the purpose of reward maximization, which levels off in early adulthood.

Next to developmental change, there was also evidence for consistency in behavior across sessions within individuals. That is, we found correlations between delay of gratification skills at T1 and $\mathrm{T} 2$, showing that participants who were better able to delay gratification at $\mathrm{T} 1$ were also better able to delay gratification at T2, which is consistent with prior studies (Audrain-McGovern et al., 2009; Anokhin et al., 2011). These results indicate a substantial level of trait-like, individual stability in delay of gratification skills in adolescence (Casey et al., 2011). These findings set the stage for examining the hypothesis in this study: how individual variation in behavior is mediated and predicted by striatumprefrontal cortex connectivity.

In a set of longitudinal analyses, we investigated the agerelated change in frontostriatal WM connections. Results indicated that the integrity of frontostriatal WM increases with age and seems to do so in a cubic fashion: the most pronounced increases in WM integrity appear to take place in preadolescence and young adulthood, with, on average, a relatively stable period in between. This finding corresponds to previous longitudinal studies demonstrating protracted maturation of large association fiber bundles (Bava et al., 2011; Lebel and Beaulieu, 2011). Studies testing for nonlinear relations in WM tracts are scarce (Olson et al. (2009) and reported similar cubic relations in WM, with the strongest changes in FA and MD during preadolescence and young adulthood. Importantly, in a longitudinal study, Simmonds et al. (2014) recently reported, in WM tracts connected to the PFC, a period of rapid growth in childhood, followed by a slowdown of growth in mid-adolescence and acceleration of growth again in late adolescence/early adulthood. Our longitudinal results also suggest a "plateau" in WM development during mid-adolescence, but this seems to be the result of larger variation in WM development during this period; some children show increases in WM integrity, whereas others remain stable or even show decreases. Our results add to increasing evidence obtained from several neuroimaging modalities showing large variability in brain activity, morphology, and connectivity during midadolescence (Scherf et al., 2012) suggesting a unique period of vulnerabilities and opportunities (Crone and Dahl, 2012). It should be noted, however, that, due to a relative smaller number of participants early adulthood $(n=21)$, the increase in WM integrity in this period must be interpreted with caution (Mills and Tamnes, 2014). Indeed, the analyses without these young adults hint toward highest values of WM integrity during late adolescence and leveling off thereafter. Therefore, replication of these results in a larger number of adults is warranted to typify the exact nature of frontostriatal WM development after adolescence.

Next, we tested whether WM integrity of frontostriatal connections was related to individual differences in the ability to delay gratification in adolescents, similar as to what has been reported previously in adults (Peper et al., 2013; van den Bos et al., 2014). Our results showed that WM integrity of the frontostriatal tract (specifically FA) mediated the relation between age and delay discounting, consistent with findings of a recent study on the relation between frontostriatal connectivity and adolescent delay discounting (van den Bos et al., 2015). However, it is not clear whether the relationship between age and delay dis- 
counting is eliminated or merely diminished when connectivity is taken into account (Steinberg and Chein, 2015). Our results on T1 show a full mediation (that the direct effect is no longer significant), whereas our results on $\mathrm{T} 2$ show a partly mediation.

Finally, we for the first time tested whether WM frontostriatal connectivity predicted change in delay discounting across development. Predicting change is important for potential early identification of adolescents who are prone to impulsive choice (see also Ullman et al., 2014). The results showed that frontostriatal WM integrity was a significant predictor of the ability to delay gratification 2 years later while taking into account delay of gratification performance at baseline. These findings indicate that brain structure is an important underlying mechanism for predicting change in behavior, whereas a reversed claim, behavior being a predictor for brain change, cannot be made based on the current study. Change in delay of gratification is partly driven by a more mature WM connectivity path between striatum and PFC.

Our current results are based on a hypothetical delaydiscounting task. According to the economic literature, not actually paying the participant for the choices on the delaydiscounting task could possibly undermine the participants' behavior as to how seriously they take the choices. Although our earlier reported results of hypothetical discounting in adults (Peper et al., 2013) were consistent with results of real discounting in adults (van den Bos et al., 2014) and several studies have shown that choices on hypothetical and real tasks significantly correlate in adults (Bickel et al., 2009; Scheres et al., 2010), it might be possible that adolescents are specifically influenced by the hypothetical aspect of our task. However, a recent study with a real-discounting task in a larger age range ( $8-25$ years; van den Bos et al., 2015) revealed similar modulating relations between structural connectivity and delay discounting, suggesting that the use of a hypothetical task might not influence the findings significantly.

In conclusion, the current study provides crucial links for our understanding of the neural mechanisms underlying delay of gratification skills. The ability to delay gratification improves between childhood and early adulthood and this is predicted by the integrity of frontostriatal WM connections. This study adds to a descriptive relation between WM integrity and delay of gratification skills by showing that maturation of frontostriatal connectivity predicts improvements in delay of gratification skills over a 2 -year period. These findings have implications for studies examining deviances in impulse control in adolescence, such as in cases of substance abuse or crime, by showing that the developmental path between striatum and PFC may be an important marker for when development goes astray.

\section{References}

Akaike H (1974) New look at statistical-model identification. IEEE Trans Automat Contr Ac 19:716-723. CrossRef

Andersson JL, Skare S (2002) A model-based method for retrospective correction of geometric distortions in diffusion-weighted EPI. Neuroimage 16:177-199. CrossRef Medline

Andersson JL, Skare S, Ashburner J (2003) How to correct susceptibility distortions in spin-echo echo-planar images: application to diffusion tensor imaging. Neuroimage 20:870-888. CrossRef Medline

Anokhin AP, Golosheykin S, Grant JD, Heath AC (2011) Heritability of delay discounting in adolescence: a longitudinal twin study. Behav Genet 41:175-183. CrossRef Medline

Audrain-McGovern J, Rodriguez D, Epstein LH, Cuevas J, Rodgers K, Wileyto EP (2009) Does delay discounting play an etiological role in smoking or is it a consequence of smoking? Drug and Alcohol Dependence 103:99-106. CrossRef Medline

Basser PJ, Pierpaoli C (1996) Microstructural and physiological features of tissues elucidated by quantitative-diffusion-tensor MRI. Journal of magnetic resonance Series B 111:209-219. CrossRef Medline

Bava S, Thayer R, Jacobus J, Ward M, Jernigan TL, Tapert SF (2010) Longitudinal characterization of white matter maturation during adolescence. Brain Res 1327:38-46. CrossRef Medline

Bava S, Boucquey V, Goldenberg D, Thayer RE, Ward M, Jacobus J, Tapert SF (2011) Sex differences in adolescent white matter architecture. Brain Res 1375:41-48. CrossRef Medline

Bickel WK, Pitcock JA, Yi R, Angtuaco EJ (2009) Congruence of BOLD response across intertemporal choice conditions: fictive and real money gains and losses. J Neurosci 29:8839-8846. CrossRef Medline

Braams BR, Peters S, Peper JS, Güroğlu B, Crone EA (2014a) Gambling for self, friends, and antagonists: differential contributions of affective and social brain regions on adolescent reward processing. Neuroimage 100: 281-289. CrossRef Medline

Braams BR, Güroğlu B, de Water E, Meuwese R, Koolschijn PC, Peper JS, Crone EA (2014b) Reward-related neural responses are dependent on the beneficiary. Soc Cogn Affect Neurosci 9:1030-1037. CrossRef Medline

Braams BR, van Duijvenvoorde AC, Peper JS, Crone EA (2015) Longitudinal changes in adolescent risk-taking: a comprehensive study of neural responses to rewards, pubertal development, and risk-taking behavior. J Neurosci 35:7226-7238. CrossRef Medline

Casey BJ (2015) Beyond simple models of self-control to circuit-based accounts of adolescent behavior. Annual Review of Psychology 66:295-319. CrossRef

Casey BJ, Somerville LH, Gotlib IH, Ayduk O, Franklin NT, Askren MK, Jonides J, Berman MG, Wilson NL, Teslovich T, Glover G, Zayas V, Mischel W, Shoda Y (2011) Behavioral and neural correlates of delay of gratification 40 years later. Proc Natl Acad Sci U S A 108:14998-15003. CrossRef Medline

Chang LC, Jones DK, Pierpaoli C (2005) RESTORE: robust estimation of tensors by outlier rejection. Magn Reson Med 53:1088-1095. CrossRef Medline

Chang LC, Walker L, Pierpaoli C (2012) Informed RESTORE: A method for robust estimation of diffusion tensor from low redundancy datasets in the presence of physiological noise artifacts. Magn Reson Med 68:1654-1663. CrossRef Medline

Christakou C, Economou F, Livadas S, Piperi C, Adamopoulos C, Marinakis E, Jdiamanti-Kandarakis E (2011) Strong and positive association of endothelin-1 with AGEs in PCOS: a causal relationship or a bystander? Hormones 10:292-297. CrossRef Medline

Critchfield TS, Kollins SH (2001) Temporal discounting: basic research and the analysis of socially important behavior. J Appl Behav Anal 34: 101-122. CrossRef Medline

Crone EA, Dahl RE (2012) Understanding adolescence as a period of socialaffective engagement and goal flexibility. Nat Rev Neurosci 13:636-650. CrossRef Medline

de Water E, Cillessen AH, Scheres A (2014) Distinct age-related differences in temporal discounting and risk taking in adolescents and young adults. Child Dev 85:1881-1897. Medline

de Zeeuw P, Mandl RC, Hulshoff Pol HE, van Engeland H, Durston S (2012) Decreased frontostriatal microstructural organization in attention deficit/hyperactivity disorder. Hum Brain Mapp 33:1941-1951. CrossRef Medline

Dixon MR, Marley J, Jacobs EA (2003) Delay discounting by pathological gamblers. J Appl Behav Anal 36:449-458. CrossRef Medline

Du WJ, Green L, Myerson J (2002) Cross-cultural comparisons of discounting delayed and probabilistic rewards. The Psychological Record 52:479492.

Eigsti IM, Zayas V, Mischel W, Shoda Y, Ayduk O, Dadlani MB, Davidson MC, Lawrence Aber J, Casey BJ (2006) Predicting cognitive control from preschool to late adolescence and young adulthood. Psychol Sci 17:478-484. CrossRef Medline

Figner B, Knoch D, Johnson EJ, Krosch AR, Lisanby SH, Fehr E, Weber EU (2010) Lateral prefrontal cortex and self-control in intertemporal choice. Nat Neurosci 13:538-539. CrossRef Medline

Green L, Fristoe N, Myerson J (1994) Temporal discounting and preference reversals in choice between delayed outcomes. Psychon Bull Rev 1: 383-389. CrossRef Medline

Jones DK (2008) Studying connections in the living human brain with diffusion MRI. Cortex 44:936-952. CrossRef Medline 
Lebel C, Beaulieu C (2011) Longitudinal development of human brain wiring continues from childhood into adulthood. J Neurosci 31:1093710947. CrossRef Medline

Le Bihan D, Breton E (1985) Imagerie de diffusion in vivo par résonance magnétique nucléaire. Compte Rendus de l'Academie de Sciences Paris 301:1109-1112.

Liston C, Watts R, Tottenham N, Davidson MC, Niogi S, Ulug AM, Casey BJ (2006) Frontostriatal microstructure modulates efficient recruitment of cognitive control. Cereb Cortex 16:553-560. Medline

McClure SM, Laibson DI, Loewenstein G, Cohen JD (2004) Separate neural systems value immediate and delayed monetary rewards. Science 306: 503-507. CrossRef Medline

Mills KL, Tamnes CK (2014) Methods and considerations for longitudinal structural brain imaging analysis across development. Dev Cogn Neurosci 9:172-190. CrossRef Medline

Mori S, Crain BJ, Chacko VP, van Zijl PC (1999) Three-dimensional tracking of axonal projections in the brain by magnetic resonance imaging. Ann Neurol 45:265-269. CrossRef Medline

Myerson J, Green L, Warusawitharana M (2001) Area under the curve as a measure of discounting. J Exp Anal Behav 76:235-243. CrossRef Medline

Olson EA, Hooper CJ, Collins P, Luciana M (2007) Adolescents' performance on delay and probability discounting tasks: contributions of age, intelligence, executive functioning, and self-reported externalizing behavior. Personality and individual differences 43:1886-1897. CrossRef Medline

Olson EA, Collins PF, Hooper CJ, Muetzel R, Lim KO, Luciana M (2009) White matter integrity predicts delay discounting behavior in 9- to 23-year-olds: a diffusion tensor imaging study. J Cogn Neurosci 21: 1406-1421. CrossRef Medline

Peper JS, Mandl RC, Braams BR, de Water E, Heijboer AC, Koolschijn PC, Crone EA (2013) Delay discounting and frontostriatal fiber tracts: a combined DTI and MTR study on impulsive choices in healthy young adults. Cereb Cortex 23:1695-1702. CrossRef Medline

Peper JS, de Reus MA, van den Heuvel MP, Schutter DJ (2015) Short fused? associations between white matter connections, sex steroids, and aggression across adolescence. Hum Brain Mapp 36:1043-1052. CrossRef Medline

Peters J, Büchel C (2011) The neural mechanisms of inter-temporal decision-making: understanding variability. Trends Cogn Sci 15:227-239. CrossRef Medline

Peters S, Koolschijn PC, Crone EA, Van Duijvenvoorde AC, Raijmakers ME (2014a) Strategies influence neural activity for feedback learning across child and adolescent development. Neuropsychologia 62:365-374. CrossRef Medline

Peters S, Braams BR, Raijmakers ME, Koolschijn PC, Crone EA (2014b) The neural coding of feedback learning across child and adolescent development. J Cogn Neurosci 26:1705-1720. CrossRef Medline

Pinheiro J, Bates D, DebRoy S, Sarkar D (2013) The R Development Core Team (2012): nlme: linear and nonlinear mixed effects models. R package version 3.1-103. Vienna: R Foundation for Statistical Computing.

Preacher KJ, Hayes AF (2008) Asymptotic and resampling strategies for assessing and comparing indirect effects in multiple mediator models. Behav Res Methods 40:879-891. CrossRef Medline

Richards JB, Zhang L, Mitchell SH, de Wit H (1999) Delay or probability discounting in a model of impulsive behavior: effect of alcohol. J Exp Anal Behav 71:121-143. CrossRef Medline

Scheres A, Dijkstra M, Ainslie E, Balkan J, Reynolds B, Sonuga-Barke E, Castellanos FX (2006) Temporal and probabilistic discounting of re- wards in children and adolescents: effects of age and ADHD symptoms. Neuropsychologia 44:2092-2103. CrossRef Medline

Scheres A, Sumiya M, Thoeny AL (2010) Studying the relation between temporal reward discounting tasks used in populations with ADHD: a factor analysis. Int J Methods Psychiatr Res 19:167-176. CrossRef Medline

Scherf KS, Behrmann M, Dahl RE (2012) Facing changes and changing faces in adolescence: a new model for investigating adolescent-specific interactions between pubertal, brain and behavioral development. Dev Cogn Neurosci 2:199-219. CrossRef Medline

Schmithorst VJ, Yuan W (2010) White matter development during adolescence as shown by diffusion MRI. Brain Cogn 72:16-25. CrossRef Medline

Schwarz G (1978) Estimating dimension of a model. Ann Stat 6:461-464. CrossRef

Simmonds DJ, Hallquist MN, Asato M, Luna B (2014) Developmental stages and sex differences of white matter and behavioral development through adolescence: a longitudinal diffusion tensor imaging (DTI) study. Neuroimage 92:356-368. CrossRef Medline

Somerville LH, Jones RM, Casey BJ (2010) A time of change: behavioral and neural correlates of adolescent sensitivity to appetitive and aversive environmental cues. Brain Cogn 72:124-133. CrossRef Medline

Somerville LH, Hare T, Casey BJ (2011) Frontostriatal maturation predicts cognitive control failure to appetitive cues in adolescents. J Cogn Neurosci 23:2123-2134. CrossRef Medline

Steinberg L, Chein JM (2015) Multiple accounts of adolescent impulsivity. Proc Natl Acad Sci U S A 112:8807-8808. CrossRef Medline

Steinberg L, Albert D, Cauffman E, Banich M, Graham S, Woolard J (2008) Age differences in sensation seeking and impulsivity as indexed by behavior and self-report: evidence for a dual systems model. Dev Psychol 44: 1764-1778. CrossRef Medline

Tabacknick B, Fidell S (2013) Using multivariate statistics, Ed 6. Boston: Pearson.

Tzourio-Mazoyer N, Landeau B, Papathanassiou D, Crivello F, Etard O, Delcroix N, Mazoyer B, Joliot M (2002) Automated anatomical labeling of activations in SPM using a macroscopic anatomical parcellation of the MNI MRI single-subject brain. Neuroimage 15:273-289. CrossRef Medline

Ullman H, Almeida R, Klingberg T (2014) Structural maturation and brain activity predict future working memory capacity during childhood development. J Neurosci 34:1592-1598. CrossRef Medline

van den Bos W, Rodriguez CA, Schweitzer JB, McClure SM (2014) Connectivity strength of dissociable striatal tracts predict individual differences in temporal discounting. J Neurosci 34:10298-10310. CrossRef Medline

van den Bos W, Rodriguez CA, Schweitzer JB, McClure SM (2015) Adolescent impatience decreases with increased frontostriatal connectivity. Proc Natl Acad Sci U S A 112:E3765-E3774. CrossRef Medline

van Duijvenvoorde AC, Achterberg M, Braams BR, Peters S, Crone EA (2016) Testing a dual-systems model of adolescent brain development using resting-state connectivity analyses. Neuroimage 124:409-420. Medline

Whelan R, Conrod PJ, Poline JB, Lourdusamy A, Banaschewski T, Barker GJ, Bellgrove MA, Büchel C, Byrne M, Cummins TD, Fauth-Bühler M, Flor H, Gallinat J, Heinz A, Ittermann B, Mann K, Martinot JL, Lalor EC, Lathrop M, Loth E, Nees F, et al.; IMAGEN Consortium (2012) Adolescent impulsivity phenotypes characterized by distinct brain networks. Nat Neurosci 15:920-925. CrossRef Medline 